\title{
Rationality in a general model of choice*
}

\author{
Somdeb Lahiri $\mathrm{a}^{*}$ \\ a IPMG, PD Petroleum University, P.O. Raisan, Gandhinagar-382007, India. \\ *Corresponding author's email address: somdeb.lahiri@yahoo.co.in
}

\section{ART T C LE INF O}

Received: 24-03-2015

Revised receipt: 24-06-2015

Accepted: 14-08-2015

Available online: 20-09-2015

Keywords:

Almost quasi-transitive,

almost transitive,

partially rational,

quasi-transitive.

JEL Classification:

\begin{abstract}
A B S T R A C T
In this paper we consider choice correspondences which may be empty-valued. We study conditions under which such choice correspondences are rational, transitively rational, partially rational, partially almost transitive rational, partially almost quasitransitive rational. This provides fresh impetus and understanding of multi-criteria decision making.
\end{abstract}

C61, D71.

(C) 2015 The Authors. This is an open access article under the terms of the Creative Commons Attribution License 4.0, which allows use, distribution and reproduction in any medium, provided the original work is properly cited.

DOI: $10.18533 /$ jefs.v3i05.111

\subsection{Introduction}

In economics the conventional method adopted to model a decision making problem is to list the set of alternatives from which the decision maker makes his choice. The act of choice is represented by a function that associates to every menu of options one or more of its chosen alternatives. Such a function is usually referred to as a choice correspondence. In such a situation, rationalization of choice is often considered to be a significant issue. While in common parlance rationalization would mean a reasoned justification, in choice theory its meaning is more specific. A rational agent is one whose act of choice results from some kind of optimizing behavior.

Much of choice theory assumes that given a finite set of alternatives, any non-empty finite subset of it could serve as a menu of options for the decision maker. In a sense such a standpoint is at variance with the origins of choice theory. In classical consumer choice theory from where a lot of choice theory arose, it is normally assumed that the consumer chooses from well defined competitive budget sets. The collection of competitive budget sets is a strict subset of the collection of non-empty subsets of the commodity space. The domain of a

\footnotetext{
${ }^{*}$ An earlier version of this paper was presented at a seminar in the Centre for Studies in Social Sciences Calcutta on June 23, 2009. I would like to thank all the seminar participants and in particular Jyotsna Jalan and Saibal Kar for their comments and suggestions. I am also grateful to Nick Baigent and Ariel Rubinstein for comments on an earlier draft of this paper. I would like to thank the anonymous referees and the editor for their useful comments that led to a substantial revision of the paper. An earlier version of this paper entitled "Choice Problems with a status-quo alternative" that is available as a SSRN Working Paper.
} 
demand function is assumed to consist of competitive budget sets only. One of the more complete discussions on choices on general domains (which allow for some sets to be excluded from consideration) can be found in Suzumura (1983). However there are equally significant situations, where it makes sense to consider the collection of all non-empty subsets as the domain of decision making. We shall not enter into the debate concerning whether it is or it is not reasonable to allow choices to be made from all subsets of a given set of alternatives. Our approach to the issue will be somewhat different.

There are two ways in which we can describe the domain of a demand function. The first and more conventional method is to say that a demand function is defined on all competitive budget sets. The alternative approach is to say that a demand function is defined on all non-empty subsets of the commodity space but disallows choices from (or assigns the empty set to) subsets which are not a competitive budget set. In a similar vein there are two ways in which we can define a choice correspondence. In the first approach we are given a collection of subsets over which the choice correspondence is defined. In the second approach the choice correspondence which is defined over all non-empty subsets disallows the act of choice from some (if any) non-empty subsets. Whether the set of choices from a given subset of alternatives is empty or not, is a property of the choice correspondence under consideration. The latter approach is what Aizerman and Aleskerov (1995) adopts to define a choice correspondence although the more significant results therein are established under the additional assumption that the decision maker does make non-empty choices from every non-empty subset of alternatives.

In this paper we consider choice correspondences that select (a possibly empty) subset from each nonempty subset of alternatives. Choice theory often considers functions that select exactly one alternative from each nonempty subset of alternatives. Such functions which are special cases of choice correspondences are naturally known as choice functions. The general idea of a choice correspondence is one that models a first stage in a choice procedure to be followed later by a second selection process that is based on some tie-breaking rule. Choice correspondences allow for greater flexibility. A particular type of a choice correspondence that some refer to as a "resolute" choice function allows at most one alternative to be chosen from every pair of alternatives. Given that this paper's concerns are about conditions under which choice correspondences are rational, if we assume that the choice correspondence is a resolute choice function then we will eventually be in a situation where at most one alternative is chosen from every non-empty set of alternatives.

As in much of economic theory where non-market phenomena are analyzed by methods which are initially motivated by models concerned with the market, our paper will concern itself with choice situations that may be far removed from consumer choice theory although we have appealed to the latter in an earlier paragraph. Unlike consumer choice theory, sets comprising two elements will play a central role in this paper. Further unlike consumer choice theory and much else that it motivates, we shall only consider a universal set of alternatives that is finite. Thus our paper is rooted in the tradition of choice theory that formally began with the seminal paper by Arrow (1959).

A type of choice correspondence we consider here is assumed to satisfy a "base domain property". This property is very similar to the one by the same name introduced by Bossert, Sprumont and Suzumura (2006), where it was assumed that the domain of a choice correspondence includes all one and two element subsets of the universal set of alternatives. On the other hand what we mean by "base domain property" is that the choice correspondence succeeds in choosing from all singletons and pairs of alternatives. Subsequently we invoke a weaker version of the base domain property that requires that given any subset of alternatives, choice is possible from each pair comprising a chosen alternative and an alternative in the subset. In the latter case all pairs need not allow non-empty choices. We call this property "weak base domain property".

A question that we are concerned with in this paper is the following. Given a choice correspondence is there a reflexive binary relation such that a chosen alternative from a subset of alternatives is at least as good as all other alternatives from the subset? Choice correspondences for which such a binary relation exists are called "partially rational". If in addition the binary relation is complete (i.e. comparable over all pairs of alternatives) then we call such a choice correspondence "rational". If the choice correspondence is at most single-valued i.e. a choice function, then in the latter case the binary relation that rationalizes the choice correspondence is clearly a "tournament" as defined for instance in Moulin (1986) or more recently in Laslier (1997). Although we seek a reflexive binary relation to "explain" choice behavior, the results we obtain in this paper would continue to survive without reflexivity, provided we are willing to allow minor alterations in the results and derivations. These alterations are fairly clear from the context in which they are intended to occur.

Two axioms that play a role in the more general context that we discuss here is the Chernoff axiom and Expansion. The Chernoff axiom says that if a chosen element from a set of alternatives is contained in a subset, then it is chosen from the subset as well. Expansion on the other hand says that if an alternative is chosen from 
two sets of alternatives then it is also chosen from their union. We are able to show that if a choice correspondence satisfies (weak) base domain property then satisfaction of Chernoff and Expansion is equivalent to it being (partially) rational. Further, if a choice function satisfies weak base domain property then satisfaction of Chernoff, Expansion and another property (Property A) is equivalent to it being partially almost transitive rational. A binary relation is said to be almost transitive if given three alternatives, if the first is at least as good as the second and the second is at least as good as the third, then it is not the case that the third is preferred to the first. Property A says that if an alternative is revealed preferred to a second and the second revealed preferred to a third then given a choice between the first and the third, the first is definitely chosen. In this context we also discuss a property called T-Congruence due Bossert, Sprumont and Suzumura (2006) and show that along with weak base domain property it implies (but is not necessarily implied by) partial almost transitive rationality. We also show that if the choice correspondence satisfies binary domain condition, then the satisfaction of Chernoff, Expansion and Property A is equivalent to transitive rationality. This follows as an immediate corollary of Proposition 2 in our paper.

Another possible relaxation of transitive binary relation that we discuss here is almost quasi-transitivity. A binary relation is said to be almost quasi-transitive if given three alternatives, if the first is preferred to the second and the second is preferred to the third then it should not be that the third is at least as good as the first. The importance of quasi-transitive rationality arises from the fact that quasi-transitive binary relations always agree with the Pareto relation generated by a non-empty finite set of linear orders. A proof of the same based on the proof of Proposition 1 of Salant and Rubinstein (2008) is provided in an appendix to this paper. In fact almost quasi-transitivity is a generalization of quasi-transitivity. We show here that satisfaction of Chernoff, Expansion and another property (Property B) is equivalent to the choice function being partially almost quasitransitive rational. Property B says that given three alternatives if in a pair-wise comparison between the first and second only the first is chosen and in a pair-wise comparison between the second and third only the second is chosen then the third is never revealed preferred to the first.

There are several questions that come to mind at this juncture. The first concerns whether there is any significant difference between our framework of choice and the framework of choice where some subsets are exogenously given to be inadmissible. It is true that the results in both frameworks appear to be similar. However, in the framework discussed in this paper whether a given subset of alternatives allows choice to be made from within it or not, is not exogenously given; it is endogenous to the choice correspondence under consideration. In our framework a subset of alternatives may disallow choice in one choice correspondence while allow it for another. This is not the case if the collection of subsets from which choice is permitted is exogenously given and invariant with respect to the choice correspondence. It is also important to bear in mind that an assumption such as weak base domain property is not easily expressible except in the kind of framework discussed in this paper.

The second question concerns the relevance of our general model of possibly empty choice sets in decision making problems. How does such a framework relate to real world decision making situations? To answer this question it is sufficient to consider an example that appears in Feldman and Serrano (2006). Suppose for instance an individual who owned both a pet dog as well as a pet cat, was asked to sacrifice one or both of his pets. In such a situation it is not difficult to imagine that the individual would have a very difficult time in deciding which of his pets he would part with and if possible would decide on parting with neither. This example was provided by Feldman and Serrano (2006) to illustrate why empty valued choices were a realistic possibility. The development of received theory is remarkably silent on such a predicament that the decision maker may face. Further, when alternatives are described by multiple attributes, the Pareto relation is incomplete. This may lead to empty choice sets. As an example consider an individual who is thinking about choosing a career. Each career is evaluated in terms of "health" (How healthy is it?) and "wealth" (How rewarding is it financially?)

It is possible that given two different careers $\mathrm{x}$ and $\mathrm{y}, \mathrm{x}$ may be healthier than $\mathrm{y}$, though $\mathrm{y}$ may be more lucrative than $\mathrm{x}$. In such a situation choosing between $\mathrm{x}$ and $\mathrm{y}$ would be impossible in the absence of further information. Thus, this paper could be considered to be a possible extension of the received theory of choice functions on finite sets as summarized in Moulin (1984).

It is worth noting that in a recent paper Rodriguez-Galiano and Gonzalez-Pachon (2001) are concerned with choice functions that are similar to the ones we discuss in this paper. Their investigation is largely about characterizing the binary relation that gives rise to a partially rational choice function, in terms of the incidence matrix of the directed graph that the binary relation gives rise to. Hence though their work is related to what we discuss here there is substantial difference as far as the approach and results between the two papers. 


\section{$2.0 \quad$ The model}

Let $\mathrm{X}$ be a non-empty finite set of alternatives and let $\Psi(\mathrm{X})$ denote the set of all non-empty subsets of $\mathrm{X}$. Let $2^{\mathrm{X}}$ denote the power set of X.

A choice correspondence is a function $\mathrm{C}: \Psi(\mathrm{X}) \rightarrow 2^{\mathrm{x}}$ such that (i) for all $\mathrm{A} \in \Psi(\mathrm{X}): \mathrm{C}(\mathrm{A})$

$\subset \mathrm{A}$; (ii) for all $\mathrm{x} \in \mathrm{X}: \mathrm{C}(\{\mathrm{x}\})=\{\mathrm{x}\}$.

A choice function is a choice correspondence which is at most single valued.

If $C$ is a choice function then there exists a function $c: \Psi(X) \rightarrow X \cup\{\phi\}$ such that (i) for all $A \in \Psi(X)$ : (i) if $C(A) \neq \phi$, then $\mathrm{C}(\mathrm{A})=\{\mathrm{C}(\mathrm{A})\}$; (ii) if $\mathrm{C}(\mathrm{A})=\phi$, then $\mathrm{c}(\mathrm{A})=\phi$.

Given a choice correspondence $C($ on $X)$ let $\operatorname{dom}(C)$ denote the set $\{A \in \Psi(X) / C(A) \neq \phi\}$, i.e. the set of all nonempty subsets of $X$ for which $C$ is non-empty valued.

Clearly for all $\mathrm{x} \in \mathrm{X}:\{\mathrm{x}\} \in \operatorname{dom}(\mathrm{C})$.

Let $\mathrm{R}_{C}$ denote the direct revealed preference relation $\bigcup_{A \in \operatorname{dom}(X)} C(A) \times A$, i.e. for all $\mathrm{x}, \mathrm{y} \in \mathrm{X}: \mathrm{xR} c \mathrm{y}$ if and only if there exists $\mathrm{A} \in \Psi(\mathrm{X})$ such that $\mathrm{x} \in \mathrm{C}(\mathrm{A})$ and $\mathrm{y} \in \mathrm{A}$; let $R_{C}^{*}=\bigcup_{A \in \operatorname{dom}(X)} C(A) \times(A \backslash C(A))$, i.e. for all $\mathrm{x}, \mathrm{y} \in \mathrm{X}: \mathrm{x} R_{C}^{*} \mathrm{y}$ if and only if there exists $\mathrm{A} \in \Psi(\mathrm{X})$ such that $\mathrm{x} \in \mathrm{C}(\mathrm{A})$ and $\mathrm{y} \in \mathrm{A} \backslash \mathrm{C}(\mathrm{A})$; and $\mathrm{R}^{\mathrm{C}}=\bigcup_{\{x, y\} \in \operatorname{dom}(X)} C(\{x, y\}) \times\{x, y\}$, i.e. for all $x, y \in X: x^{C} y$ if and only if $x \in C(\{x, y\})$.

A choice correspondence $\mathrm{C}$ is said to be partially rational if there exists a binary relation $\mathrm{R}$ on $\mathrm{X}$ satisfying the following:

(1) $\mathrm{R}$ is reflexive: For all $\mathrm{x} \in \mathrm{X}, \mathrm{xRx}$;

(2) For all $\mathrm{A} \in \operatorname{dom}(\mathrm{C}): \mathrm{C}(\mathrm{A})=\{\mathrm{x} \in \mathrm{A}$ : for all $\mathrm{y} \in \mathrm{A}$, $\mathrm{xRy}\}$.

In this case $\mathrm{R}$ is said to be a partial rationalization of $\mathrm{C}$.

A partial rationalization $\mathrm{R}$ of $\mathrm{C}$ is said to be a rationalization of $\mathrm{C}$ if $\mathrm{R}$ is complete, i.e. for all $\mathrm{x}, \mathrm{y} \in \mathrm{X}$ with $\mathrm{x} \neq \mathrm{y}$ : either xRy or yRx.

If a choice correspondence $\mathrm{C}$ has a rationalization then we say that it is rational.

The original version of the following property is due to Bossert, Sprumont and Suzumura (2006).

Base domain property: A choice correspondence C is said to satisfy the Base Domain Property (BD) if for all $\mathrm{x}, \mathrm{y} \in \mathrm{X}:\{\mathrm{x}, \mathrm{y}\} \in \operatorname{dom}(\mathrm{C})$.

In other words, the base domain property requires that the decision maker is able to choose from every two element set (and thus does not opt for the status-quo).

A weaker version of the above property is the following:

Weak base domain property: A choice correspondence $C$ is said to satisfy the Weak Base Domain property (WBD) if for all $\mathrm{A} \in \Psi(\mathrm{X}), \mathrm{x} \in \mathrm{C}(\mathrm{A})$ and $\mathrm{y} \in \mathrm{A}$ with $\mathrm{x} \neq \mathrm{y}:\{\mathrm{x}, \mathrm{y}\} \in \operatorname{dom}(\mathrm{C})$.

Two axioms that are well known in the choice theory literature are the following.

Chernoff axiom: A choice correspondence $C$ is said to satisfy Chernoff Axiom (CA) if for all $A \in \Psi(X)$ and $B \in$ $\operatorname{dom}(\mathrm{C}):[\mathrm{B} \subset \mathrm{A}]$ implies $[\mathrm{C}(\mathrm{A}) \cap \mathrm{B} \subset \mathrm{C}(\mathrm{B})]$.

Expansion (E): A choice correspondence $C$ is said to satisfy Expansion (E) if for all $A, B \in \Psi(X)$ with $\mathrm{A} \cup \mathrm{B} \in \operatorname{dom}(\mathrm{C}): \mathrm{C}(\mathrm{A}) \cap \mathrm{C}(\mathrm{B}) \subset \mathrm{C}(\mathrm{A} \cup \mathrm{B})$.

\subsection{Partial rational choice and weak base domain property}

\section{Proposition 1:}

Let $\mathrm{C}$ be a choice correspondence satisfying WBD. Then $\mathrm{C}$ is partially rational if and only if $\mathrm{C}$ satisfies $\mathrm{CA}$ and $\mathrm{E}$.

Proof:

Let $\mathrm{C}$ be a choice correspondence satisfying WBD. 
a. Suppose C satisfies CA and E.

Let $\mathrm{A} \in \operatorname{dom}(\mathrm{C})$.

Let $\mathrm{x} \in \mathrm{C}(\mathrm{A})$. Then $\mathrm{xR}$ cy for all $\mathrm{y} \in \mathrm{A}$. Thus $\mathrm{C}(\mathrm{A}) \subset\{\mathrm{x} \in \mathrm{A}$ : $\mathrm{xR}$ cy for all $\mathrm{y} \in \mathrm{A}\}$.

On the other hand if $x \in A$ and $x R_{c} y$ for all $y \in A$, then for all $y \in A$ there exists a set $A_{y} \in \operatorname{dom}(C)$ such that $y \in A_{y}$ and $\mathrm{x} \in \mathrm{C}\left(\mathrm{A}_{\mathrm{y}}\right)$.

By WBD, $\{\mathrm{x}, \mathrm{y}\} \in \operatorname{dom}(\mathrm{C})$ for all $\mathrm{y} \in \mathrm{A}$.

By $C A$ applied to $A_{y}$ and $\{x, y\}$ we get that $x \in C(\{x, y\})$ for all $y \in A$.

By $\mathrm{E}$ and since $\mathrm{A}=\bigcup_{y \in A}\{x, y\}$ we get $\mathrm{x} \in \bigcap_{y \in A} C(\{x, y\}) \subset \mathrm{C}(\mathrm{A})$.

Thus $\{\mathrm{x} \in \mathrm{A}$ : $\mathrm{xR}$ cy for all $\mathrm{y} \in \mathrm{A}\} \subset \mathrm{C}(\mathrm{A})$.

Combining the two inclusions we get that $C(A)=\left\{x \in A\right.$ : $x R_{c} y$ for all $\left.y \in A\right\}$.

Clearly $R_{C}$ is reflexive. Thus $C$ is partially rational with $R_{C}$ being a partial rationalization of $C$.

b. In the other direction, suppose $\mathrm{C}$ is partially rational.

Thus there exists a binary relation $\mathrm{R}$ on $\mathrm{X}$ satisfying the following:

1. $\mathrm{R}$ is reflexive: For all $\mathrm{x} \in \mathrm{X}, \mathrm{xRx}$;

2. For all $\mathrm{A} \in \operatorname{dom}(\mathrm{C}): \mathrm{C}(\mathrm{A})=\{\mathrm{x} \in \mathrm{A}$ : for all $\mathrm{y} \in \mathrm{A}$, $\mathrm{xRy}\}$.

Let $\mathrm{A} \in \Psi(\mathrm{X})$ and $\mathrm{B} \in \operatorname{dom}(\mathrm{C}), \mathrm{B} \subset \mathrm{A}$ and $\mathrm{x} \in \mathrm{C}(\mathrm{A}) \cap \mathrm{B}$.

Thus $A \in \operatorname{dom}(\mathrm{C})$ and $\mathrm{xRy}$ for all $\mathrm{y} \in \mathrm{A}$.

Hence $x$ Ry for all $y \in B$.

Since $C$ is partially rational with $R$ being a partial rationalization, in view of $B \in \operatorname{dom}(C)$ we get $x \in C(B)$. Thus $C$ satisfies CA.

Now let $\mathrm{A}, \mathrm{B} \in \Psi(\mathrm{X})$ with $\mathrm{A} \cup \mathrm{B} \in \operatorname{dom}(\mathrm{C})$ and $\mathrm{x} \in \mathrm{C}(\mathrm{A}) \cap \mathrm{C}(\mathrm{B})$. Thus $\mathrm{A}, \mathrm{B} \in \operatorname{dom}(\mathrm{C})$.

If $y \in A$ then since $x \in C(A)$ we get $x$ R.

On the other hand if $y \in B$ then since $x \in C(B)$ we get $x$ Ry. Thus $x \in C(A \cup B)$ and $C(A) \cap C(B) \subset C(A \cup B)$. Thus $C$ satisfies E. Q.E.D.

While proving the above proposition we established the following result:

Let $\mathrm{C}$ be a choice correspondence satisfying WBD. If $\mathrm{C}$ satisfies $\mathrm{CA}$ and $\mathrm{E}$, then $\mathrm{R}_{\mathrm{C}}$ is a partial rationalization of $\mathrm{C}$. An immediate corollary of Proposition 1 is the following:

Corollary of proposition 1 :

Let $\mathrm{C}$ be a choice correspondence satisfying BD. Then $\mathrm{C}$ is rational if and only if $\mathrm{C}$ satisfies CA and E. A binary relation $\mathrm{R}$ on $\mathrm{X}$ is said to be transitive if for all $\mathrm{x}, \mathrm{y}, \mathrm{z} \in \mathrm{X}$ : [xRy \& $\mathrm{yRz}]$ implies [xRz].

A choice correspondence $\mathrm{C}$ is said to be (partially) transitively rational if there exists a (partial) rationalization $\mathrm{R}$ of $\mathrm{C}$ that is transitive. We now provide an example of a choice correspondence that satisfies BD, CA and E but is not transitively rational.

Example 1:

Let $X=\{x, y, z, u\} ; C(\{a\})=\{a\}$ for all $a \in X, C(A \cup\{u\})=\{u\}$ for all non-empty subsets $A$ of $\{x, y, z\}, C(\{x, y\})=\{x\}$, $\mathrm{C}(\{\mathrm{y}, \mathrm{z}\})=\{\mathrm{y}\}, \mathrm{C}(\mathrm{z}, \mathrm{x}\})=\{\mathrm{z}\}, \mathrm{C}(\{\mathrm{x}, \mathrm{y}, \mathrm{z}\})=\phi$. It is easy to see that $\mathrm{C}$ satisfies BD, CA and $\mathrm{E}$.

Suppose $\mathrm{R}$ is any rationalization of $\mathrm{C}$. Then $\mathrm{R}$ is not transitive since we have $\mathrm{xRyRz}$ but notxRz.

It is worth noting that if instead of defining $C A$ as we have in this paper, we had defined it as "for all $A \in \Psi(X)$ and $\mathrm{B} \in \Psi(\mathrm{X}):[\mathrm{B} \subset \mathrm{A}]$ implies $[\mathrm{C}(\mathrm{A}) \cap \mathrm{B} \subset \mathrm{C}(\mathrm{B})]$ " then by Proposition 1 we would get that if $\mathrm{C}$ satisfied WBD, $\mathrm{CA}$ and $\mathrm{E}$ then $C$ is partially rational. In this stronger version of $C A$ we are relaxing the requirement that $B$ belongs to $\operatorname{dom}(\mathrm{C})$ for $[\mathrm{B} \subset \mathrm{A}]$ to imply $[\mathrm{C}(\mathrm{A}) \cap \mathrm{B} \subset \mathrm{C}(\mathrm{B})]$

This makes CA a stronger assumption than what we have defined it to be in the paper. However, there exist partially rational choice correspondences which satisfy WBD and E but which do not satisfy this stronger version of our CA. An example of such a choice correspondence could be obtained from example 1 by assuming $\mathrm{C}(\{\mathrm{a}, \mathrm{u}\})=\{\mathrm{u}\}$ for all $\mathrm{a} \in\{\mathrm{x}, \mathrm{y}, \mathrm{z}\}, \mathrm{C}(\{\mathrm{a}, \mathrm{b}, \mathrm{u}\})=\phi$ for all $\mathrm{a}, \mathrm{b} \in\{\mathrm{x}, \mathrm{y}, \mathrm{z}\}$ with $\mathrm{a} \neq \mathrm{b}, \mathrm{C}(\mathrm{X})=\{\mathrm{u}\}, \mathrm{C}(\{\mathrm{x}, \mathrm{y}\})=\{\mathrm{x}\}, \mathrm{C}(\{\mathrm{y}, \mathrm{z}\})=$ $\{y\}, C(z, x\})=\{z\}, C(\{x, y, z\})=\phi$. This $C$ satisfies WBD, E and is partially rationalized by any $R$ that partially rationalizes the choice correspondence in example 1 . It also satisfies our version of CA but not the stronger version: $\{\mathrm{u}, \mathrm{x}, \mathrm{y}\} \subset \mathrm{X}$, but $\mathrm{u} \in[\mathrm{C}(\mathrm{X}) \cap\{\mathrm{u}, \mathrm{x} . \mathrm{y}\}] \backslash \mathrm{C}(\{\mathrm{u}, \mathrm{x}, \mathrm{y}\})$. In fact $\{\mathrm{u}, \mathrm{x}, \mathrm{y}\}$ does not belong to $\operatorname{dom}(\mathrm{C})$. 


\subsection{Partial almost transitive and almost quasi-transitive rationality}

Given a binary relation $\mathrm{R}$ on $\mathrm{X}$ let $\mathrm{P}(\mathrm{R})$ denote the asymmetric part of $\mathrm{R}$ (i.e. for all $\mathrm{x}, \mathrm{y} \in \mathrm{X}: \mathrm{xP}(\mathrm{R}) \mathrm{y}$ if and only if xRy but not $[\mathrm{yRx}]$ ) and $\mathrm{I}(\mathrm{R})$ its symmetric part (i.e. for all $\mathrm{x}, \mathrm{y} \in \mathrm{X}: \mathrm{xI}(\mathrm{R}) \mathrm{y}$ if and only if $\mathrm{xRy}$ and $[\mathrm{yRx}])$. A binary relation $\mathrm{R}$ on $\mathrm{X}$ is said to be almost transitive if there does not exist three distinct alternatives $\mathrm{x}, \mathrm{y}, \mathrm{z} \in \mathrm{X}$ such that $\mathrm{xRy}, \mathrm{yRz}$ and $\mathrm{zP}(\mathrm{R}) \mathrm{x}$.

If in Example 1 above we put $\mathrm{C}(\{\mathrm{z}, \mathrm{x}\})=\phi$ then $\mathrm{C}$ becomes partially almost transitively rational with $\mathrm{R}$ reflexive and $u P(R) a$ for all $a \in X \backslash\{u\}, x P(R) y, y P(R) z$ being a partial almost transitive rationalization of $C$. In fact we can make this partial rationalization complete and transitive by assuming $\mathrm{x}(\mathrm{R}) \mathrm{z}$ as well.

A choice correspondence $\mathrm{C}$ is said to be partially almost transitive rational if there exists a partial rationalization $\mathrm{R}$ of $\mathrm{C}$ that is almost transitive.

Property A:

A choice correspondence $C$ is said to satisfy Property $A$ if for all

$\mathrm{x}, \mathrm{y}, \mathrm{z} \in \mathrm{X}:[\mathrm{xRcy}, \mathrm{yRcz}$ and $\{\mathrm{x}, \mathrm{z}\} \in \operatorname{dom}(\mathrm{C})]$ implies $[\mathrm{x} \in \mathrm{C}(\{\mathrm{x}, \mathrm{z}\})]$.

\section{Proposition 2:}

Let $\mathrm{C}$ be a choice correspondence that satisfies WBD. C is partially almost transitive rational if and only if $\mathrm{C}$ satisfies CA, E and Property A.

Proof:

Suppose $\mathrm{C}$ is a choice correspondence that satisfies WBD, CA, E and Property A. By the first three properties we get that $C$ is partially rational with $R_{C}$ being a partial rationalization of $C$.

Let $x, y, z \in X$ with $x R_{c} y$ and $y R_{c} z$. Towards a contradiction suppose that $z P\left(R_{c}\right) x$. Thus $z R_{c x}$.

Hence there exists $\mathrm{A} \in \operatorname{dom}(\mathrm{C})$ such that $\mathrm{z} \in \mathrm{C}(\mathrm{A})$ and $\mathrm{x} \in \mathrm{A}$.

By WBD, $\{\mathrm{x}, \mathrm{z}\} \in \operatorname{dom}(\mathrm{C})$.

By Property A we get $\mathrm{x} \in \mathrm{C}(\{\mathrm{x}, \mathrm{z}\})$ contradicting $\mathrm{zP}\left(\mathrm{R}_{\mathrm{C}}\right) \mathrm{x}$. Thus $\mathrm{R}_{\mathrm{c}}$ is almost transitive rational.

Now suppose $\mathrm{C}$ is partially almost transitive rational with $\mathrm{R}$ being the necessary partial almost transitive rationalization.

Thus for all $\mathrm{A} \in \operatorname{dom}(\mathrm{C}): \mathrm{C}(\mathrm{A})=\{\mathrm{x} \in \mathrm{A}$ : $\mathrm{xRy}$ for all $\mathrm{y} \in \mathrm{A}\}$.

By Proposition 1, C satisfies CA and E. Let us show that $C$ satisfies Property A.

Let $\mathrm{x}, \mathrm{y}, \mathrm{z} \in \mathrm{X}$ with $\mathrm{xR} c \mathrm{y}, \mathrm{yRcz}$ and $\{\mathrm{x}, \mathrm{z}\} \in \operatorname{dom}(\mathrm{C})$. Towards a contradiction suppose that $\mathrm{x} \notin \mathrm{C}(\{\mathrm{x}, \mathrm{z}\})$. Thus $\mathrm{C}(\{\mathrm{x}, \mathrm{z}\})$

$=\{\mathrm{z}\}$.

Hence $z P(R) x$.

$x R y, y R z$ and $z P(R) x$ contradicts the almost transitivity of R. Thus $C$ satisfies Property A. Q.E.D.

The following corollary of Proposition 2 is easily established.

Corollary of proposition 2:

Let $\mathrm{C}$ be a choice correspondence that satisfies BD. C is transitive rational if and only if $\mathrm{C}$ satisfies CA, E and Property A.

In Bossert, Sprumont and Suzumura (2006) we can find a stronger version of the Weak Congruence Axiom due to Richter (1966). This stronger version is referred to as T-Congruence. A choice correspondence $C$ is said to satisfy T-Congruence if for all $\mathrm{x}, \mathrm{y}, \mathrm{z} \in \mathrm{X}$ and $\mathrm{A} \in \operatorname{dom}(\mathrm{C})$ : $[\mathrm{xRcy}, \mathrm{yRcz}, \mathrm{x} \in \mathrm{A}$ and $\mathrm{z} \in \mathrm{C}(\mathrm{A})]$ implies $[\mathrm{x} \in \mathrm{C}(\mathrm{A})]$.

The special case where $y=z$ corresponds to the definition of Weak Congruence.

Bossert, Sprumont and Suzumura (2006) show that provided a choice correspondence satisfies BD it is transitive rational if and only if it satisfies T-Congruence. On the other hand, if we merely assume that a choice correspondence satisfies WBD then we cannot obtain such a strong result. What we can show is the following.

\section{Proposition 3:}

Let $\mathrm{C}$ be a choice function that satisfies WBD. If C satisfies T-Congruence then it is almost transitively rational. The converse is however not true.

Proof: Let $C$ satisfy WBD and T-Congruence. Let $\mathrm{A} \in \operatorname{dom}(\mathrm{C})$.

If $x \in C(A)$ then $x$ Rcy for all $y \in A$. Thus $C(A) \subset\left\{x \in A\right.$ : $x R_{c} y$ for all $\left.y \in A\right\}$. 
Now suppose $\mathrm{x} \in \mathrm{A}$ and $\mathrm{xRcy}$ for all $\mathrm{y} \in \mathrm{A}$.

Since for all $y \in A$ we have $y R c y$, it follows by $T$-Congruence that $x \in C(A)$. Thus $\{x \in A$ : $x R c y$ for all $y \in A\} \subset C(A)$.

Combining the two inclusions we get $\mathrm{C}(\mathrm{A})=\{\mathrm{x} \in \mathrm{A}$ : $\mathrm{xR}$ cy for all $\mathrm{y} \in \mathrm{A}\}$.

Clearly $R_{C}$ is reflexive. Now let us show that $R_{C}$ is almost transitive.

Let $\mathrm{x}, \mathrm{y}, \mathrm{z} \in \mathrm{X}$ with $\mathrm{xR} c \mathrm{y}$ and $\mathrm{yRcz}$. Towards a contradiction suppose that $\mathrm{zP}(\mathrm{Rc}) \mathrm{x}$.

Then there exists $\mathrm{A} \in \operatorname{dom}(\mathrm{C})$ such that $\mathrm{z} \in \mathrm{C}(\mathrm{A})$ and $\mathrm{x} \in \mathrm{A} \backslash \mathrm{C}(\mathrm{A})$. However [xRcy and $\mathrm{yRcz}, \mathrm{A} \in \operatorname{dom}(\mathrm{C}), \mathrm{z} \in \mathrm{C}(\mathrm{A})$ and $\mathrm{x} \in \mathrm{A}]$ implies by $\mathrm{T}$-Congruence that $[\mathrm{x} \in \mathrm{C}(\mathrm{A})]$, contradicting $[\mathrm{x} \in \mathrm{A} \backslash \mathrm{C}(\mathrm{A})]$.

Thus not $\mathrm{zP}\left(\mathrm{R}_{\mathrm{C}}\right) \mathrm{x}$ and hence $\mathrm{R}_{\mathrm{C}}$ is almost transitive. Thus $\mathrm{C}$ is partially almost transitive rational.

To show that the converse is not true let $X=\{x, y, z\}$. Let $C(\{x, y\})=\{x, y\}, C(\{y, z\})=\{y, z\}, C(\{x, z\})=\phi$ and $C(X)=$ $\{\mathrm{y}\}$. Clearly $\mathrm{C}$ is partially almost transitive rational with $\mathrm{R}^{\mathrm{C}}$ being the necessary partial almost transitive rationalization. However, $C$ does not satisfy T-congruence since $x R c y, y R c y, y \in C(X)$ and $x \in X \backslash C(X)$. Q.E.D.

A binary relation $\mathrm{R}$ on $\mathrm{X}$ is said to be quasi-transitive if given $\mathrm{x}, \mathrm{y}, \mathrm{z} \in \mathrm{X}:[\mathrm{xP}(\mathrm{R}) \mathrm{y}$ and $\mathrm{yP}(\mathrm{R}) \mathrm{z}]$ implies $[\mathrm{xP}(\mathrm{R}) \mathrm{z}]$. A binary relation $\mathrm{R}$ on $\mathrm{X}$ is said to be almost quasi-transitive if there does not exist three distinct alternatives $\mathrm{x}, \mathrm{y}, \mathrm{z}$ $\in \mathrm{X}$ such that $\mathrm{XP}(\mathrm{R}) \mathrm{y}, \mathrm{yP}(\mathrm{R}) \mathrm{z}$ and $\mathrm{zRx}$.

It is easy to see that a binary relation that is almost transitive is also almost quasi-transitive, though the converse need not be true. A choice correspondence $\mathrm{C}$ is said to be partially almost quasi-transitive rational if there exists a partial rationalization $\mathrm{R}$ of $\mathrm{C}$ that is almost quasi-transitive.

Property B:

A choice correspondence $C$ is said to satisfy Property B if for all $x, y, z \in X:[\{x\}=C(\{x, y\}) \&\{y\}=C(\{y, z\})]$ implies [not $\left.\mathrm{zR}_{\mathrm{Cx}}\right]$.

\section{Proposition 4:}

Let $\mathrm{C}$ be a choice correspondence that satisfies WBD. C is partially almost quasi-transitive rational if and only if $\mathrm{C}$ satisfies CA, E and Property B.

Proof:

Suppose C is a choice correspondence that satisfies WBD, CA, E and Property B. By the first three properties we get that $\mathrm{C}$ is partially rational with $\mathrm{R}_{\mathrm{C}}$ being a partial rationalization of $\mathrm{C}$.

Let $\mathrm{x}, \mathrm{y}, \mathrm{z} \in \mathrm{X}$ with $\mathrm{xP}(\mathrm{Rc}) \mathrm{y}, \mathrm{yP}(\mathrm{Rc}) \mathrm{z}$.

Thus there exists $\mathrm{A}, \mathrm{B} \in \operatorname{dom}(\mathrm{C})$ such that $\mathrm{x} \in \mathrm{C}(\mathrm{A}), \mathrm{y} \in \mathrm{C}(\mathrm{B}) \cap(\mathrm{A} \backslash \mathrm{C}(\mathrm{A}))$ and $\mathrm{z} \in \mathrm{B} \backslash \mathrm{C}(\mathrm{B})$.

By WBD, $\{\mathrm{x}, \mathrm{y}\},\{\mathrm{y}, \mathrm{z}\} \in \operatorname{dom}(\mathrm{C})$.

By $C A$ and $x P\left(R_{C}\right) y$ we get $\{x\}=C(\{x, y\})$.

By $C A$ and $y P\left(R_{C}\right) z$ we get $\{y\}=C(\{y, z\})$.

Thus by Property B we get notzRcx. Thus Rc is almost quasi-transitive.

Now suppose $\mathrm{C}$ is partially almost quasi-transitive rational with $\mathrm{R}$ being the necessary partial almost quasitransitive rationalization.

Thus for all $\mathrm{A} \in \operatorname{dom}(\mathrm{C}): \mathrm{C}(\mathrm{A})=\{\mathrm{x} \in \mathrm{A}$ : $\mathrm{xRy}$ for all $\mathrm{y} \in \mathrm{A}\}$.

By Proposition 1, C satisfies CA and E. Let us show that C satisfies Property B.

Let $\mathrm{x}, \mathrm{y}, \mathrm{z} \in \mathrm{X}$ with $\{\mathrm{x}\}=\mathrm{C}(\{\mathrm{x}, \mathrm{y}\}) \&\{\mathrm{y}\}=\mathrm{C}(\{\mathrm{y}, \mathrm{z}\})$. Towards a contradiction suppose that $\mathrm{zR}_{\mathrm{C}} \mathrm{x}$.

Thus $\mathrm{xP}(\mathrm{R}) \mathrm{y}$ and $\mathrm{yP}(\mathrm{R}) \mathrm{z}$ and $\mathrm{zRx}$, contradicting the almost quasi-transitivity of R. Hence C satisfies Property $\mathrm{B}$. Q.E.D.

A choice correspondence $\mathrm{C}$ is said to be (partially) quasi-transitive rational if there exists a (partial) rationalization $\mathrm{R}$ of $\mathrm{C}$ that is quasi-transitive. The following corollary of Proposition 4 is easy to establish.

Corollary of proposition 4 :

Let $\mathrm{C}$ be a choice correspondence that satisfies $\mathrm{BD}$. $\mathrm{C}$ is quasi-transitive rational if and only if $\mathrm{C}$ satisfies $\mathrm{CA}, \mathrm{E}$ and Property B.

Remark: Bossert, Sprumont and Suzumura (2006) contains the following axiom that is used by them in characterizing quasi-transitive rational choice. 
Q-Congruence: A choice correspondence $\mathrm{C}$ is said to satisfy $\mathrm{Q}$-Congruence if for all $\mathrm{x}, \mathrm{y}, \mathrm{z} \in \mathrm{X}:[\mathrm{xP}(\mathrm{Rc}) \mathrm{y} \& \mathrm{yP}(\mathrm{Rc}) \mathrm{z}]$ implies [notzRcx].

The following lemma helps us to establish a connection between Property B and Q-Congruence.

Lemma 1:

Let $\mathrm{C}$ be a choice correspondence that satisfies CA.

a. C satisfies Property B if it satisfies Q-Congruence.

b. C satisfies Q-Congruence if it satisfies WBD and Property B.

Proof:

Let C satisfy CA.

a. Suppose $C$ satisfies Q-Congruence and let $\mathrm{x}, \mathrm{y}, \mathrm{z} \in \mathrm{X}$ with $\{\mathrm{x}\}=\mathrm{C}(\{\mathrm{x}, \mathrm{y}\}) \&\{\mathrm{y}\}=\mathrm{C}(\{\mathrm{y}, \mathrm{z}\})$.

Since $\{\mathrm{x}\}=\mathrm{C}(\{\mathrm{x}, \mathrm{y}\})$ it follows that $\{\mathrm{x}, \mathrm{y}\} \in \operatorname{dom}(\mathrm{C})$ and $\mathrm{xR} c \mathrm{y}$.

Towards a contradiction suppose $y R c x$. Thus there exists $\mathrm{A} \in \operatorname{dom}(\mathrm{C})$ such that $\mathrm{y} \in \mathrm{C}(\mathrm{A})$ and $\mathrm{x} \in \mathrm{A}$.

Since $\{\mathrm{x}, \mathrm{y}\} \in \operatorname{dom}(\mathrm{C})$ by CA it follows that $(\mathrm{y} \in) \mathrm{C}(\mathrm{A}) \cap\{\mathrm{x}, \mathrm{y}\} \subset \mathrm{C}(\{\mathrm{x}, \mathrm{y}\})$ contradicting our hypothesis that $\{\mathrm{x}\}=$ $\mathrm{C}(\{\mathrm{x}, \mathrm{y}\})$.

Thus notyRcx and hence $\mathrm{xP}\left(\mathrm{R}_{\mathrm{C}}\right) \mathrm{y}$.

Similarly yP(Rc)z.

By Q-Congruence we get notzRcx. Thus C satisfies Property B.

b. Now suppose $C$ satisfies WBD and Property B.

Let $x, y, z \in X$ with $x P(R c) y \& y P(R c) z$.

$\mathrm{xP}\left(\mathrm{R}_{\mathrm{c}}\right) \mathrm{y}$ implies $\mathrm{xR}$ cy.

By WBD we get that $\{\mathrm{x}, \mathrm{y}\} \in \operatorname{dom}(\mathrm{C})$.

Since $x P\left(R_{C}\right) y, y \notin C(\{x, y\})$.

Thus $\{\mathrm{x}\}=\mathrm{C}(\{\mathrm{x}, \mathrm{y}\})$.

Similarly $\{y\}=C(\{y, z\})$.

By Property B, notzRcx. Thus C satisfies Q-Congruence. Q.E.D.

The next proposition is an immediate consequence of Proposition 4 and Lemma1.

Proposition 5:

Let $\mathrm{C}$ be a choice correspondence that satisfies WBD. $\mathrm{C}$ is partially almost quasi-transitive rational if and only if $\mathrm{C}$ satisfies CA, E and Q-Congruence. As a result of the above we obtain the following corollary.

Corollary of proposition 5 :

Let $\mathrm{C}$ be a choice correspondence that satisfies BD. $\mathrm{C}$ is quasi-transitive rational if and only if $\mathrm{C}$ satisfies $\mathrm{CA}, \mathrm{E}$ and Q-Congruence.

It may be wondered whether the main results of this paper are tight. For instance, given a partially almost transitive (almost quasi-transitive) rational choice function, is it possible to extend the almost transitive (quasitransitive) base relation to a transitive (quasi-transitive) binary relation that also partially rationalizes the given choice function? The following example which is a variation of example 1 shows that this may not be possible.

Example 2:

Let $X=\{x, y, z, u\} ; C(\{a\})=\{a\}$ for all $a \in X, C(\{x, y\})=\{x\}, C(\{y, z\})=\{y\}, C(z, x\})=C(\{x, y, z\})=\phi, C(\{u, y\})=$ $C(\{u, z\})=\{u\}, C(\{u, x\})=C(\{u, x, y\})=\{u, x\}, C(\{u, x, z\})=C(\{u, y, z\})=\{u\}$ and $C(X)=\{u\}$. It is easy to see that $C$ is partially almost transitive rational with $\mathrm{R}^{C}$ being the almost transitive partial rationalization of $\mathrm{C}$.

Suppose towards a contradiction $\mathrm{R}$ is a partially transitive rationalization of $\mathrm{C}$. In such a situation we would require $x R y, y R z, x R z$ and $x R u$. However, the partial rationalization of $C$ by $R$ would then imply $x \in C(X)$, contrary to hypothesis. Thus $\mathrm{C}$ cannot be partially rationalized by any transitive binary relation.

\subsection{The general model of choice and dynamic choice theory}

The importance of possibly empty-valued choice correspondences arise not only under situations where for a given set of alternatives the "act of choice" becomes impossible, but also under situations where certain sets of alternatives or opportunity sets do not/may not arise. This is particularly true in the case of an extremely active area of research in decision theory namely "dynamic choice theory". The modern framework of dynamic choice theory originates in the seminal paper of Kreps (1979). In this framework, a decision maker is faced with a two- 
period choice problem. In the first period the decision maker chooses an alternative and along with that alternative an opportunity set from among a non-empty collection of opportunity sets that are available with that alternative. In the second period the decision maker chooses an alternative from the opportunity set that he chose in the first period. Those opportunity sets which are not available to the decision maker in the first stage are the ones, from which the "act of choice" during the second period becomes impossible. This is typically the case in capital budgeting or portfolio choice problems, where along with an investment made in the initial period one has to choose terms and conditions leading to opportunities that arise only in a future period.

\subsection{Conclusion}

In this paper we have discussed choice correspondences that may be empty valued. This framework throws up possibilities that are absent in the classical framework of choice theory. In particular we study transitive and quasi-transitive rationalizability of choice correspondences. As observed in the introduction and established in an appendix of this paper, quasi-transitive rational choice is equivalent to multi-criteria optimization. Or multicriteria decision making (MCDM).

This is only a modest beginning that has been made in a more general setting than what choice theory has been mainly concerned with. Much remains to be done if we want to understand fully the scope and nature of the kind of choice correspondences that we discuss here.

\section{References}

Aizerman, M.A. and Aleskerov, F. (1995): "Theory of Choice." Elsevier North Holland, Amsterdam.

Arrow, K.J. (1959): "Rational choice functions and orderings." Economica, 26, 121-7. http://dx.doi.org/10.2307/2550390

Bossert, W., Sprumont, Y. and Suzumura, K. (2006): "Rationalizability of choice functions on general domains without full transitivity," Social Choice Welfare 27, 435-458. http://dx.doi.org/10.1007/s00355-006-0132-0

Feldman, A.M. and Serrano, R. (2006): "Welfare Economics and Social Choice Theory" (2nd Edition). Springer Science + Business Media Inc.

Kreps, D.M. (1979): "A representation theorem for preference for flexibility", Econometrica 47, 565-577. http://dx.doi.org/10.2307/1910406

Laslier, J.-F. (1997): "Tournament solutions and majority voting." Volume 7 in the series "Studies in Economic Theory", Springer Verlag, Heidelberg, New York. http://dx.doi.org/10.1007/978-3-642-60805-6

Moulin, H. (1984): "Choice functions over a finite set: a summary," Social Choice Welfare 2, 147-160. http://dx.doi.org/10.1007/BF00437315

Moulin, H. (1986): "Choosing from a tournament." Social Choice Welfare 3, 271-291. http://dx.doi.org/10.1007/BF00292732

Richter, M.K. (1966): "Revealed preference theory." Econometrica 34, 635-645. http://dx.doi.org/10.2307/1909773

Rodriguez-Galiano, I. and Gonzalez-Pachon, J. (2001): "Characterization of certain orders using their associated choice functions." European Journal of Operational Research 132, 619-627. http://dx.doi.org/10.1016/S0377-2217(00)00166-1

Salant, Y. and Rubinstein, A. (2008): "(A,f): Choices with Frames", The Review of Economic Studies 75, 12871296. http://dx.doi.org/10.1111/j.1467-937X.2008.00510.x

Suzumura, K. (1983): "Rational Choice, Collective Decisions and Social Welfare." New York: Cambridge University Press. http://dx.doi.org/10.1017/CBO9780511897993 


\section{Appendix}

Given an asymmetric binary relation $P$ on $X$ and $A \in Q(X)$ let $M(A, P)=\{x \in A \mid$ there does not exist $y \in A$ such that yPx\}.

An asymmetric binary relation $\mathrm{P}$ on $\mathrm{X}$ is said to be total if for all $\mathrm{x}, \mathrm{y} \in \mathrm{X}$, with $\mathrm{x} \neq \mathrm{y}$, either $\mathrm{xPy}$ or $\mathrm{yPx}$. An asymmetric binary relation on $\mathrm{X}$ which is both total and transitive is said to be a linear order.

\section{Claim:}

If $>$ is a linear order on $X$, then for all $A \in Q(X): M(A,>)$ is a singleton.

\section{Proposition:}

Let $\mathrm{P}$ be an asymmetric and transitive binary relation on $\mathrm{X}$. Then, there exists a non-empty finite set $\mathrm{F}$ of linear orders on $\mathrm{X}$, such that for all $\mathrm{A} \in \mathrm{Q}(\mathrm{X}): \mathrm{M}(\mathrm{A}, \mathrm{P})=\mathrm{U}_{>\in F} M(A,>)$.

Proof (Based on Proposition 1 of Salant and Rubinstein (2008)):

For every $\mathrm{x} \in \mathrm{X}$, let $>_{\mathrm{x}}$ be an extension of $\mathrm{P}$ to a linear order on $\mathrm{X}$, in which only the elements in the set $\{\mathrm{y} \in \mathrm{X} \mid \mathrm{yPx}\}$ are ranked above $x$. This is achieved in the following manner: Let $X^{0}(x)=\{y \in X \mid y P x\} \cup\{x\}, A^{1}(x)=M\left(X^{0}(x), P\right)$, $\mathrm{X}^{1}(\mathrm{x})=\mathrm{X}^{0}(\mathrm{x}) \backslash \mathrm{A}^{1}(\mathrm{x})$. Having defined $\mathrm{A}^{\mathrm{k}}(\mathrm{x})$ and $\mathrm{X}^{\mathrm{k}}(\mathrm{x})$ for $\mathrm{k} \geq 1$, stop if $\mathrm{X}^{\mathrm{k}}(\mathrm{x})=\phi$. If $\mathrm{X}^{\mathrm{k}}(\mathrm{x}) \neq \phi$, then let $\mathrm{A}^{\mathrm{k}+1}(\mathrm{x})=$ $M\left(X^{k}(x), P\right)$ and $X^{k+1}(x)=X^{k+1}(x) \backslash A^{k+1}(x)$. Since $X$ and hence $X^{0}(x)$ is finite, there exist a least positive integer $K$ such that $\mathrm{A}^{\mathrm{K}}(\mathrm{X})=\mathrm{X}^{\mathrm{K}-1}(\mathrm{x})$.

Let $\mathrm{Y}^{0}(\mathrm{x})=\mathrm{X} \backslash \mathrm{X}^{0}(\mathrm{x})$. If $\mathrm{Y}^{0}(\mathrm{x})=\phi$, the procedure stops here. Otherwise let $\mathrm{B}^{1}(\mathrm{x})=\mathrm{M}\left(\mathrm{Y}^{0}(\mathrm{x}), \mathrm{P}\right), \mathrm{Y}^{1}(\mathrm{x})=\mathrm{Y}^{0}(\mathrm{x}) \backslash$ $\mathrm{B}^{1}(\mathrm{x})$. Having defined $\mathrm{B}^{\mathrm{k}}(\mathrm{x})$ and $\mathrm{Y}^{\mathrm{k}}(\mathrm{x})$ for $\mathrm{k} \geq 1$, stop if $\mathrm{Y}^{\mathrm{k}}(\mathrm{x})=\phi$. If $\mathrm{Y}^{\mathrm{k}}(\mathrm{x}) \neq \phi$, then let $\mathrm{B}^{\mathrm{k}+1}(\mathrm{x})=\mathrm{M}\left(\mathrm{Y}^{\mathrm{k}}(\mathrm{x}), \mathrm{P}\right)$ and $\mathrm{Y}^{\mathrm{k}+1}(\mathrm{x})=\mathrm{Y}^{\mathrm{k}+1}(\mathrm{x}) \backslash \mathrm{B}^{\mathrm{k}+1}(\mathrm{x})$. Since $\mathrm{X}$ and hence $\mathrm{Y}^{0}(\mathrm{x})$ is finite, there exist a least positive integer $\mathrm{L}$ such that $\mathrm{B}^{\mathrm{L}}(\mathrm{x})$ $=\mathrm{X}^{\mathrm{L}-1}(\mathrm{X})$.

Let $>_{\mathrm{x}}$ be any linear ordering on $\mathrm{X}$ such its restriction to $\mathrm{X}^{0}(\mathrm{x})$ satisfying the following properties: (i) for all $y \in \mathrm{X}^{0}(\mathrm{x})$ and $\mathrm{z} \in \mathrm{Y}^{0}(\mathrm{x}), \mathrm{y}>\mathrm{xz}$; (ii) for all $\mathrm{y}, \mathrm{z} \in \mathrm{X}^{0}(\mathrm{x})$, $\left[\mathrm{y} \in \mathrm{A}^{\mathrm{k}}(\mathrm{x}), \mathrm{z} \in \mathrm{A}^{\mathrm{j}}(\mathrm{x})\right.$ and $\mathrm{k}<\mathrm{j}$ ] implies [y $>_{\mathrm{x}}$ ]; (iii) for all $\mathrm{y}, \mathrm{z} \in \mathrm{Y}^{0}(\mathrm{x}),\left[\mathrm{y} \in \mathrm{B}^{\mathrm{k}}(\mathrm{x}), \mathrm{z} \in \mathrm{B}^{\mathrm{j}}(\mathrm{x})\right.$ and $\left.\mathrm{k}<\mathrm{j}\right]$ implies $[\mathrm{y}>\mathrm{xz}]$

Let $F=\left\{>_{x} \mid x \in X\right\}$.

Let $\mathrm{x}, \mathrm{y} \in \mathrm{X}$ be such that $\mathrm{xPy}$. Then, clearly $\mathrm{x}>_{\mathrm{x}} \mathrm{y}$ and $\mathrm{x}>_{\mathrm{y}} \mathrm{y}$.

Let $\mathrm{z} \in \mathrm{X} \backslash\{\mathrm{x}, \mathrm{y}\}$.

If either $\mathrm{zPx}$ or $\mathrm{yPz}$ then it is not possible for $\mathrm{y}$ to be chosen while $\mathrm{x}$ is still available in the dynamic process by which we define $>_{z}$. This follows from the transitivity of P. Nor is it possible (due to the transitivity of P) for $y$ to be chosen while $x$ is still available if $x P z$ and $z P y$.

If $\mathrm{xPz}, \neg \mathrm{zPy}$ and $\neg \mathrm{yPz}$, then $\mathrm{x} \in \mathrm{X}^{0}(\mathrm{z})$ and $\mathrm{y} \in \mathrm{Y}^{0}(\mathrm{z})$. Hence $\mathrm{x}>_{\mathrm{z}} \mathrm{z}>_{\mathrm{z}} \mathrm{y}$ and so $\mathrm{x}>\mathrm{z} \mathrm{y}$.

If $\mathrm{zPy}, \neg \mathrm{zPx}$ and $\neg \mathrm{xPz}$ then both $\mathrm{x}$ and $\mathrm{y}$ belong to $\mathrm{Y}^{0}(\mathrm{z})$ and it is not possible for $\mathrm{y}$ to be chosen while $\mathrm{x}$ is still available in the dynamic process that defines $>_{\mathrm{z}}$. Thus, $\mathrm{x}>_{\mathrm{z} y}$.

If $\neg \mathrm{zPx}, \neg \mathrm{xPz}, \neg \mathrm{zPy}$ and $\neg \mathrm{yPz}$ then also both $\mathrm{x}$ and $\mathrm{y}$ belong to $\mathrm{Y}^{0}(\mathrm{z})$ and it is not possible for $\mathrm{y}$ to be chosen while $\mathrm{x}$ is still available in the dynamic process that defines $>_{\mathrm{z}}$. Thus, $\mathrm{x}>_{\mathrm{z}} \mathrm{y}$.

Let $\mathrm{x} \in \mathrm{U}_{>\in F} M(A,>), \mathrm{y} \in \mathrm{A}$ and towards a contradiction suppose $\mathrm{yPx}$. Then, for all $\mathrm{z} \in \mathrm{X}, \mathrm{y}>_{\mathrm{z}} \mathrm{X}$, contradicting $\mathrm{x} \in$ $U_{>\in F} M(A,>)$. Thus, $\mathrm{x} \in \mathrm{U}_{>\in F} M(A,>) \subset \mathrm{M}(\mathrm{A}, \mathrm{P})$.

Now suppose, $x \in M(A, P)$. Then there does not exist $y \in A$ such that $y P x$. Thus, $x>_{x y}$ for all $y \in A \backslash\{x\}$ and so $x \in M(A$, $>_{\mathrm{x}}$ ). Thus, $\mathrm{x} \in \mathrm{U}_{>\in F} M(A,>)$ and so $\mathrm{M}(\mathrm{A}, \mathrm{P}) \subset \mathrm{U}_{>\in F} M(A,>)$. Thus, $\mathrm{U}_{>\in F} M(A,>)=\mathrm{M}(\mathrm{A}, \mathrm{P})$. Q.E.D. 